\title{
O PROBLEMA DA EXPERIÊNCIA ESTÉTICA COMO FUNDAMENTO DA DEFINIÇÃO DE ARTE EM NOËL CARROLL E A IDENTIFICAÇÃO NARRATIVA
}

\author{
Guilherme Mautone \\ Mestrando em Filosofia PPG-FIL/UFRGS, bolsista CAPES \\ guimautone@gmail.com
}

\begin{abstract}
Resumo: $O$ trabalho procura abordar alguns pontos importantes da análise oferecida por Noël Carroll da teoria estética da arte contemporânea de Beardsley e sua implicação definicional, evidenciando em que sentido ela é problemática para uma compreensão adequada do estatuto da arte. $\bigcirc$ trabalho também apresenta resumidamente a proposta de Carroll ao problema da identificação da arte, denominada narrativas identificadoras.
\end{abstract}

Gostaria de abordar, ao longo deste trabalho, a análise oferecida por Noël Carroll das consequências filosóficas de um comprometimento forte com a definição estética da arte que aparecerá no horizonte do debate contemporâneo da Filosofia da Arte.

Ao redor da definição estética da arte sideram uma série de empreendimentos teóricos variados, novos e antigos, analíticos e continentais, 
que se apresentam ao leitor atual como um conjunto muito diverso de 'teorias estéticas da arte'.' Elas, no entanto, possuem um núcleo definicional comum, marcado pelo regime do bicondicional que amarra logicamente o seu definiendum ('arte') ao definiens 'experiência estética'.

Para nós contemporâneos, familiarizados com o arrojamento interno da arte (especialmente a Conceitual), com a ênfase na experimentação e no processo artístico, com a desmaterialização do suporte (para empregar os termos de Lucy Lippard) e, finalmente, com a miscigenação das formas artísticas (ao contrário do que pretendeu o Classicismo de Lessing), a definição estética da arte e suas teorias nos parecerão anacrônicas. Ainda assim, a definição estética reaparece atualmente diante de nós, disfarçada de Crítica de Arte, e com pretensões de arregimentar certa normatividade e de legislar sobre decisões importantes no mundo da arte.

A discussão sobre a definiçãa da arte, contudo, recobre-se de um interesse prático e nos aponta uma necessidade cotidiana: a de identificar objetos, às vezes demasiadamente heteróclitos, enquanto 'obras de arte'. E o abandono de uma definição anteriormente aceitável através da demonstração de sua inviabilidade atual oportunizará que se ofereça uma perspectiva reconstrutiva, capaz de atenuar o ceticismo e de instaurar o mínimo de acerto epistêmico - afinal de contas a questão de fundo será, sempre, sobre a correção ou a incorreção do nosso conhecimento.

Dividi o texto em três seções. Na primeira, procurarei reproduzir as partes que considero mais relevantes da análise feita por Carroll das 'teorias estéticas da arte', em especial o empreendimento teórico de Monroe Beardsley. Na segunda, tentarei mostrar em que sentido a definição estética da arte (encontrada em Beardsley) é filosoficamente inadequada em razão de uma dupla inconsistência. E, por fim, na terceira parte, procurarei mostrar como Carroll, tendo sugerido o abandono da definição estética, pretende resolver o problema da identificação de obras de arte.

\footnotetext{
${ }^{1}$ CARroll, N. Beyond Aesthetics, p. 5.
} 


\section{Seção I: A estética de Beardsley}

Monroe Beardsley, filósofo norte-americano, publica em 1958 seu Aesthetics: Problems in the Philosophy of Criticism, obra influenciada principalmente pelo Novo Criticismo, corrente literária que procurava apresentar uma via alternativa às críticas psicanalítica, sócio-cultural, marxista e formalista que medravam no horizonte intelectual da época. Seu trabalho também pretendia oferecer uma consideração valorativa à obra de arte, capaz de informar o seu traço diferencial e específico, distinto das demais produções humanas. Traço que era, para Beardsley, a experiência estética. Sua obra se desenvolve fundamentalmente no sentido de fornecer aos leitores uma consideração contemporânea desse tipo específico de experiência que é compartilhada por todos os objetos artísticos e que evidencia o seu valor. Assim, o conceito de experiência estética é construído por Beardsley em dois momentos, recebendo nuances diferentes em cada um deles.

Primeiramente, a experiência estética será apresentada como o resultado de um processo consumatório da apreensão de segmentos qualitativos do campo fenomênico dos sujeitos que se encontram organizados em um arranjo específico de propriedades. A consumação da experiência estética será, nesse primeiro momento, inteiramente dependente de uma disposição muito particular dessas propriedades intrínsecas dos objetos que, assim dispostas, ofereceriam aos sujeitos a oportunidade de um encontro capaz de promovê-la. A organização destes segmentos qualitativos, para Beardsley, respeitará na maioria das vezes um arranjo que relaciona parte $X$ todo, onde as partes discerníveis se encontram unificadas em um todo, conferindo à coisa um caráter único.

Em seus trabalhos mais tardios, Beardsley se afastará dessa concepção que enfatiza as propriedades dos objetos, aproximando-se de outra que procurará explicitar com maior cuidado o caráter único da própria experiência. É bastante provável que este afastamento se deva a uma preocupação em não reintroduzir teoricamente, nesta segunda consideração sobre a arte e seu valor 
estético, os subsídios mais fundamentais de teorias formalistas (de Clive Bell e Roger Fry), e que motivaram uma reação frontal por parte de Beardsley em 1958. Embora as posições assumidas por ele em seus trabalhos recentes e as posições da crítica formalista sejam distintas e empreguem, também, conceitos diferentes de experiência estética; ainda assim elas dependem igualmente de um compromisso filosófico com a existência de propriedades qualitativas inerentes às coisas. Nesse sentido, falar em 'propriedades do objeto' ou em 'forma significativa' é falar em qualidades específicas, responsáveis pela consumação da experiência estética, e que se encontram nos objetos. É muito provavelmente por essa razão que Beardsley tenha se afastado de um desenvolvimento mais extensivo da experiência estética a partir da noção de propriedades objetivas para, mais tarde, reelabora-la sob bases epistêmicas, cuja ênfase será o sujeito.

Já a concepção mais tardia proposta por Beardsley é desenvolvida a partir do que ficará conhecido entre os comentadores como argumento dos atributos da experiência. Ele será construído em bases condicionais e oferecerá, para a consumação da experiência estética, cinco condições diferentes de engajamento epistêmico por parte dos sujeitos, que são: (1) Direcionalidade da experiência ao objeto, ou seja, o sujeito deve concentrar nele a sua experiência, direcionando suas faculdades para a sua contemplação; (2) sensação de liberdade, ou seja, esse processo deve ser marcado por um traço de autonomia, no qual o sujeito volta sua atenção livremente ao objeto sem que haja necessidade ou obrigatoriedade; (3) afetos desinteressados, ou seja, a experiência não pode ser marcada por uma expectativa quanto aos seus resultados, desenvolvendo-se na dimensão do desinteresse kantiano; (4) inteireza, ou seja, a experiência deve resultar de uma vivência marcada pela totalidade do direcionamento e pela sensação de 'imersão'; e (5) descoberta ativa, ou seja, a experiência deve ser marcada por uma sensação de 
desvelamento, de acontecimento aberto, no qual o sujeito figura como parte central da experiência. ${ }^{2}$

A concepção contemporânea da experiência estética fornecida por Beardsley motivou, e continua motivando, exegeses bastante relevantes e que procuram, ainda hoje, determinar a natureza do estético e a dimensão que ele ocupa na vida humana. É inegável que o trabalho de Beardsley seja marcado, de um lado, por um arrojamento conceitual muito característico para a experiência estética e, de outro, por uma complexidade única. A dimensão funcionalista que se atribuiu ao seu pensamento consiste, assim, na evidenciação de que a definição de arte é por ele concebida a partir da função que estes objetos desempenham, marcadamente a função de promover a experiência estética. ${ }^{3}$ Também é importante reconhecer em Beardsley um esforço significativo em fornecer as condições e em explicitar as distinções primeiro fenomenológicas e, depois, epistêmicas - de um tipo muito específico de experiência. Ainda que esse esforço nos pareça muito relevante da perspectiva da reflexão filosófica dentro do domínio da estética, nota-se certa opacidade por parte do autor ao explorar as intersecções desse arrojado desenvolvimento da experiência com as reflexões sobre a natureza da arte.

É curioso, portanto, que o primeiro capítulo do seu Aesthetics seja dedicado a uma 'ontologia da arte' e que Beardsley se esquive tão cuidadosamente da necessidade, imposta por qualquer ontologia, de fornecer uma consideração minimamente adequada sobre a natureza daquilo mesmo que pretende estudar. O termo 'arte', empregado no título, é logo substituído pelo autor pelo termo 'objeto estético' ao longo do texto, fornecendo a ele a oportunidade de desenvolver uma ontologia da estética e não da obra de arte. É somente mais tarde, em um pós-escrito à segunda edição de Aesthetics, de 1981, que Beardsley justificará sua escolha em desviar-se dessa consideração, alegando que não gostaria de ter-se "enredado" na questão de uma definição de arte, já que tal questão não o "convencia de sua importância ou prometia

\footnotetext{
${ }^{2}$ BEARDSLEY, M. The Aesthetic Point of View, p. 288-289.

${ }^{3}$ CARROLL, N. Beyond Aesthetics, p. 20.
} 
qualquer resolução satisfatória e adequada". ${ }^{4}$ Ler seus trabalhos recentes sem levar em consideração o Postscript 1980 da segunda edição sugere, é certo, que Beardsley efetivamente partira de uma concepção conjuntiva das noções de 'experiência estética' e de 'obra de arte'. É só um ano depois da publicação da segunda edição de Aesthetics (a que traz o pós-escrito) que Beardsley finalmente expõe com clareza os contornos da questão. Assim, em The Aesthetics Point of View, torna-se evidente o que ficara implícito. Uma definição de arte deverá, para ele, "conectar conceitualmente arte e estética". ${ }^{5}$

Ainda que os interesses, as motivações e o contexto histórico que tenham suscitado a primeira edição de Aesthetics em 58 não tenham mostrado a Beardsley a necessidade de uma evidenciação mais clara da sua definição estética da arte, seu comprometimento com ela pode ser assegurado pelos trabalhos tardios. É evidente que este compromisso não significava ou correspondia às expectativas que ele mesmo impunha a si mesmo na construção da obra de 58, já que sua preocupação naquele momento se concentrava em oferecer uma via alternativa para a compreensão da arte e de seu valor, filosoficamente fundamentada e capaz de fornecer bases epistemológicas seguras e claras para um criticismo ainda nascente.

\section{Seção II: A definição estética da arte}

Noël Carroll afirma, na introdução de seu Beyond Aesthetics, que é preciso ir "além das teorias estéticas da arte e suas diversas proibições (...) não identificando a essência da arte com aquela pretensa capacidade das obras de arte de fornecerem experiências estéticas". 6 Gostaria de analisar, ainda que brevemente, estas proibições e em que sentido elas geram profundas restrições conceituais que impossibilitam que identifiquemos produções altamente relevantes para a arte e para a filosofia como, por exemplo, os readymades ou os objets trouvé de Duchamp, grande parte da Arte Conceitual, John Cage e sua música silenciosa e assim por diante.

\footnotetext{
${ }^{4}$ CARroll, N. Aesthetics: Problems in the Philosophy of Criticism, p. 4.

${ }^{5}$ BEARDSLEY, M. The Aesthetic Point of View, p. 6.

${ }^{6}$ CARROLL, N. Beyond Aesthetics, p. 1.
} 
grande problema da definição estética da arte consiste numa dupla inconsistência. Por um lado, essa definição é demasiadamente restrita, deixando de lado pretendentes importantes ao estatuto da arte. E, por outro lado, ela é demasiadamente abrangente, incluindo no conceito 'arte' entidades e fenômenos que não o são efetivamente. O arranjo condicional tramado pelas credenciais lógicas dessa definição, frente à inovação ontológica da produção artística moderna e contemporânea, acaba, portanto, implicando estas duas consequências. O arranjo deixa de fora do escopo do conceito 'arte' itens altamente relevantes ao estabelecer condições que nem toda obra de arte efetivamente preenche; e o arranjo também incluí no escopo do conceito itens sabidamente não-artísticos ao estabelecer condições que não são exclusivas à arte. Assim, o emprego da noção de experiência estética na definição de arte gera uma definição que é, ao mesmo tempo, inclusiva (para itens não relevantes) e exclusiva (para itens relevantes). Aceitar a definição estética da arte nos obriga a aceitar que Roda de Bicicleta (1913) de Duchamp e Brillo Soap Pads Box (1964) de Warhol não são obras de arte já que não são objetos comprometidos com a produção da experiência estética, e sim com outros objetivos (por exemplo, problematizar o suporte tradicional e a própria definição de arte enquanto 'objeto estético' e/ou em estabelecer mecanismos de autorreferência). Outra consequência da aceitação da definição estética da arte seria a obrigatoriedade em aceitarmos que a experiência que eu tive mais cedo em meu desjejum, ao comer biscoitos e tomar chá (fazendo referência à famosa descrição de uma experiência estética no Em Busca do Tempo Perdido de Marcel Proust) e que foi marcada por um caráter consumatório, de inteireza, de direcionalidade da minha atenção e de liberdade, é - de direito - uma obra de arte.

A dupla inconsistência da definição estética da arte que acabei de apontar só se dá em função de um abrupto deslocamento lógico, que faz amalgamar e imiscuir categorias diametralmente distintas, já que a defesa de que 'só é arte aquilo que promove experiência estética' implica que o conjunto 'arte' se converta, instantaneamente, em um subconjunto do 'estético'. Isso sem 
maiores digressões sobre a outra possibilidade (de serem conjuntos iguais, sobrepostos), o que excluiria completamente a apreciação estética de coisas naturais (não-criadas pelo homem) e o tão importante 'belo natural' kantiano. Essa explicitação bastante breve das consequências lógicas e ontológicas acarretadas pela definição estética da arte suscita a necessidade (senão a urgência) de um descredenciamento filosófico desse tipo de definição enquanto tentativa de exprimir com exatidão a natureza da arte.

\section{Seção III: A virada narrativa}

O abandono de uma via definicional para a identificação da arte (no caso a definição estética), suscita oportunidade para que se considere outra definição que não acarrete os mesmos desacertos ou uma alternativa inédita para identificação que não dependa de definições. A proposta de Carroll consistirá, portanto, por um abandono da via definicional (como o fez Morris Weitz em seu The Role of Theory in Aesthetics, influenciado pelos desenvolvimentos wittgensteinianos de Investigações Filosóficas e de $O$ Livro Azul). Assim, a noção de 'semelhanças de família' não será utilizada, como em Weitz, para a comparação de objetos com os estereótipos de um paradigma determinado, facultando a concessão do estatuto 'arte' ao objeto comparado.' Em Carroll, a proposta não será anti-definicional, mas não-definicional. $\bigcirc$ problema da definição da arte será colocado em parêntesis, suscitando a consideração um método de identificação próprio.

O método das narrativas identificadoras oferecido por Carroll consiste em um procedimento filosófico que permite a identificação de itens ontológicos qua arte sem definição, que opera através da elaboração de relatos não-ficcionais capazes de explicitar razões que conectam historicamente aquele objeto que se disputa ou se pretende mostrar como 'obra de arte' a uma tradição artística amplamente reconhecida e inserida na própria história da arte. A identificação proposta por Carroll se dará sempre pela produção de narrativas conceituais que forneçam uma espécie de linhagem artística a determinado objeto,

\footnotetext{
${ }^{7}$ WEITZ, M. The Role of Theory in Aesthetics, p. 30-31.
} 
mostrando-o como herdeiro de uma tradição, ainda que ela tenha mudado radicalmente ao longo da história.

A narrativa identificadora será, assim, uma narrativa não-ficcional, mas teórica, dotada de início, meio e fim e que discrimine e descreva como um objeto $x$ participa, reproduz, reencena, contraria, reafirma, radicaliza, desconstrói ou imita contextos, cenas, preocupações, princípios e/ou objetivos presentes na realização ou na construção de outros itens tradicionalmente reconhecidos como 'arte', alinhando o objeto $x$ ao cânone artístico ou ao conjunto de obras de arte efetivas que o sujeito que duvida que ' $x$ é arte' dispõe como referência deste conceito. Dessa maneira, mostrar que 'x é arte' dependerá da disposição e da competência em elaborar uma narrativa capaz de colocar x numa linha sucessória com a tradição. Mostrando, por exemplo, que

- $x$ recupera as experimentações vanguardistas realizadas por Duchamp;

- que Duchamp radicaliza e inverte a definição de 'arte' como 'objeto belo' ou 'objeto que proporciona beleza' ao construir A Fonte (1917) e Roda de Bicicleta (1913);

- que a 'arte' pré-Duchamp não havia conseguido, ainda, radicalizar o suporte, mas já havia conseguido explorar seu meio de expressão no Impressionismo e em Cézanne;

- que Cézanne efetuara uma virada no final do séc. XIX ao chamar atenção para a cor, o traço, a composição, ao invés de insistir no tema e na imitação;

- que os Neoclassicistas, como Ingres e Jacques-Louis David, não haviam se preocupado em abandonar a imitação, mas preocupavam-se principalmente com a sua maestria;

- e assim por diante, até um momento específico da história da arte que operará como parâmetro para a narrativa.

Não é preciso ir mais longe no exemplo para chamar a atenção para o fato de que as narrativas identificadoras de Carroll são bastante simples e que 
procuram demonstrar em que sentido o objeto $x$ está inserido na temporalidade, contextualidade e racionalidade da própria história da arte.

A crítica carrolliniana às 'teorias estéticas da arte' desempenha, em seu pensamento, o papel de motor teórico para o desenvolvimento de uma abordagem própria para a identificação artística dentro do debate contemporâneo sobre a oscilação definicional do termo ao longo da história. Ainda que não efetue uma aplicação indistinta das ideias wittgensteinianas ou weitzianas em sua abordagem filosófica, Carroll adentrará este debate com um método próprio, marcado por uma compreensão particular do sentido e da dimensão de história da arte e por uma perspectiva de retorno à concretude dos casos particulares.

O background das narrativas identificadoras de Carroll será sempre a história da arte. Talvez ela não seja compreendida somente como um amontoado de artefatos ou como uma sequência ordenada de eventos. Essa imagem, embora caricatural, dá ensejo para que se considere o sentido que se quer dar para a história da arte em sua contribuição filosófica. Parece-me que, ao contrário da caricatura, a história da arte para Carroll recebe a acepção de um conjunto complexo de práticas, técnicas e conceitos compartilhados ao longo do tempo e, a cada tempo, repensados e discutidos por novos sujeitos, que são seus 'usuários'. A transmissão dessas práticas, técnicas, termos, conceitos, bem como o processo de discussão e de contribuição por parte desses novos 'usuários', é o que muito provavelmente Carroll entenda por história da arte. A imagem a ser pensada aqui não é a da linearidade, mas talvez (e assumo o risco da comparação) à daquela velha cidade que fala Wittgenstein em Investigações Filosóficas ao longo do $\S 18$ e que nos daria um insight a respeito da natureza e do funcionamento da linguagem (WITTGENSTEIN, 2009). ${ }^{8}$

\footnotetext{
${ }^{8}$ WITTGENSTEIN, L. Philosophische Untersuchungen - Philosophical Investigations, p. 13e.
} 


\section{Bibliografia}

CARROLL, N. Beyond Aesthetics: Philosophical Essays. Cambridge: Cambridge University Press, 2001.

BEARDSLEY, M. Aesthetics: Problems in the Philosophy of Criticism (19 edição). Nova lorque: Harcourt Brace \& World, 1958.

BEARDSLEY, M. Aesthetics: Problems in the Philosophy of Criticism (29 edição). Indianapolis: Hackett, 1981.

BEARDSLEY, M. The Aesthetic Point of View. Ithaca: Cornell University Press, 1982.

WEITZ, M. "The Role of Theory in Aesthetics". The Journal of Aesthetics and Art Criticism, vol. XV / no. 1 (1957), p. 27-35.

WITTGENSTEIN, L. Philosophische Untersuchungen - Philosophical Investigations. Tradução: ANSCOMBE, G., HACKER, P. \& SCHULTE, J. Oxford: Basil-Blackwell, 2009. 